\title{
Preliminary Evaluation of Platelet Counts of Diabetic Individuals Attending University of Maiduguri Teaching Hospital
}

\author{
Y. P. Mamza ${ }^{1}$, H.D. Goji ${ }^{2}$, J.T. Medugu ${ }^{3}$, A.B.G. Peyou ${ }^{4}$ \\ 1, 2, 3, 4 (Department Of Medical Laboratory Science, College Of Medical Sciences, University Of Maiduguri,
} Nigeria)

\begin{abstract}
Hyperglycaemia hyperactivates platelets functions which in turn participates in the pathophysiology of vasculopathies in diabetics. This study was carried out to investigate the platelet counts of the various diabetic groups attending University of Maiduguri Teaching Hospital and compare to non-diabetic group. This is a case-control study that comprises of 220 subjects. Out of 120 confirmed diabetic subjects, three subgroups of $2(1.7 \%)$ type 1 diabetics, 101 (84.1\%) type 2 diabetics and 17 (14.2\%) gestational diabetics comprised the test participants while 100 non-diabetic subjects served as control participants. Platelet counts and plasma glucose estimation were carried out using standard testing protocols. Findings from this study indicated no significant difference between the means of platelet counts of the diabetics subgroups and control participants $(p>0.05)$.The mean platelet counts was significantly $(p<0.05)$ lower in patients with type 2 diabetics compared to those with gestational diabetics $\left(315.37 \pm 56.13 \times 10^{9}\right.$ cells $/ l$ versus $\left.325.82 \pm 56.78 \times 10^{9} \mathrm{cells} / \mathrm{l}\right)(p<0.05)$. There was a positive but not significant correlation ( $r=0.052 ; p>0.05)$ between platelet counts and glycemic status of diabetic subjects. Routine platelet counts result is a good index for evaluation thrombotic function of diabetic patients, but more useful in conjunction with testing the overall functionality of the coagulation cascades.
\end{abstract}

Keywords: Platelet, Diabetes, Haemostasis; Thrombosis

\section{Introduction}

Diabetes mellitus (DM) is a family of metabolic disorders characterized by the presence of chronic hyperglycemia that is either immune-mediated, due to insulin resistance, gestational or due to other causes (environment, genetic defects, infections, and certain drugs) [1]. Corkey [2] defined DM as fasting glucose concentrations of above $7 \mathrm{mmol} / \mathrm{l}$, or above $11 \mathrm{mmol} / \mathrm{l}$ two hours after ingestion of 75 grams of glucose.

Type 2 diabetes is more prevalent than type 1 diabetes and is associated with a substantially increased risk of macrovascular complications [3].The prevalence of diabetic vasculopathies is higher in people with poor glycaemic control, longer duration of DM, and associated hypertension and obesity [4]. Gestational diabetes mellitus (GDM) or impaired glucose tolerance which is characterized by a hyperinsulinemic state and a decrease of tissues receptors to insulin, affects between 3-10\% of all pregnancies [5][6]. The consequences of GDM lead to increased prenatal and maternal morbidity and mortality [7].DM is alluded to be found in every population in the world and epidemiological evidence suggests that, without effective prevention and control programmes, diabetes will likely continue to increase globally [8].

The metabolic derangements associated with diabetes can adversely influence platelet and vascular endothelial activity, which may contribute to pathogenesis of diabetic angiopathy [9]. Platelets from diabetic subjects show increased reactivity [10].Vaidyula et al. [11] reported platelet hypereactivity in healthy subjects without diabetes after induction of hyperglycaemia and hyperinsulinaemia. In agreement with previous studies, improved glycemic control has been linked with decreased platelet reactivity [9].The hyperglycemia at the base of diabetes contributes to greater platelet reactivity through direct effects and by promoting glycation of platelet proteins [3]. One way hyperglycemia can cause platelet hypereactivity is by inducing non-enzymatic glycation of proteins on the surface of the platelet. The glycation decreases membrane fluidity which in turn increases the tendency of platelets to activate [12]. In another mechanism, hyperglycemia increase platelet reactivity by osmotic effect of glucose. According to Schneider [3], a brief exposure of platelets in vitro to hyperglycemia increased their reactivity. Assert et al. [13] demonstrated that in vivo activation of protein C kinase, being a transduction pathway mediator of platelet activation, is another mechanism by which hyperglycaemia can cause platelet hypereactivity. The final common pathway of platelet activation is platelet aggregation, mediated by the glycoprotein IIb/IIIa receptor (GPIIb/IIIa) platelet-fibrin interaction. Hyperglycaemia leads to release of larger platelets with more GPIb and GPIIb/IIIa receptors and higher thromboxane forming capacity [14].

In individuals with insulin resistance or insulin deficiency, Insulin normally antagonizes the effect of platelet agonists such as collagen, ADP, epinephrine, and platelet-activating factor [15]. The insulin antagonism is mediated by activation of an inhibitory G protein by insulin receptor substrate (IRS)-1. Insulin resistance reflects impaired insulin signaling, predominantly mediated by IRS. Thus, resistance by the platelet to the 
effects of insulin (relative insulin deficiency) or absolute deficiency of insulin attenuates insulin mediated antagonism of platelet activation and thereby increases platelet reactivity [3] [16].

Chronic hyperglycaemia, the sine qua non of diabetes causes derangements in many physiological functions related to haemostasis [17]. There is platelet hypereaction and platelet turnover; leading to increased platelet adhesion and aggregation enhanced expression of platelet surface adhesion molecules and receptors [18]. The mean platelet volume, platelet counts and other platelet parameters may significantly aid the identification of diabetics at risk for vascular complications [19]. Platelet counts and mean platelet volume are characteristics of platelet. These are simple and viable indicators of platelet activation and can be used as biomarkers for risk of macrovascular complications in diabetics [5] [20].

Several reports compared and/or correlate platelet parameters as measure of platelet activity in diabetics and non-diabetics [5] [18] [19] [20]. Platelet count was an unavoidable parameter measured. In view of these, the present study sought to determine the platelet counts among the various diabetic groups and correlate with fasting plasma glucose which is could be an essential marker of haemostatic derangements in diabetes.

Study area

\section{Methods}

This study was carried out in the Haematology Department, University of Maiduguri Teaching Hospital (UMTH), Maiduguri, Nigeria. UMTH is a major referral medical centre in the North eastern Nigeria, with 500 bed size and sub-specialties in medicine and training of other health care professionals. Maiduguri is the capital of Borno state, which lies on latitude $115^{\circ} \mathrm{N}$ and longitude $135^{\circ} \mathrm{E}$, and occupies an area of 50,778 square kilo meters.

\section{Study population}

A total of 220 subjects were recruited for this study, which comprises of 120 clinically diagnosed diabetic subjects and 100 non-diabetic subjects as control.

\section{Sample size determination}

The sample size was determined from a standard formula for the calculation of sample size.

$$
\text { Sample size } \boldsymbol{n}=\left(\mathrm{Z}_{1-\mathrm{a}}\right)^{2} \times \mathrm{P}(1-\mathrm{P})
$$

Where $\boldsymbol{n}=$ minimum sample size,

$\mathrm{Z}_{1-\mathrm{a}}=$ value of standard normal deviation which is at $95 \%$ confidence level has been found to be 1.96 .

$\mathrm{P}=$ best estimate of the population prevalence obtained from the literature review.

$\mathrm{d}=$ proportion of sample error in a given population.

At prevalence rate of Diabetes mellitus of $8.3 \%$ [21], using 5\% precision at $95 \%$ confidence level, the minimum sample size $\boldsymbol{n}$ for this study is calculated as follows:

Sample size $\boldsymbol{n}=\left(\mathrm{Z}_{1-\mathrm{a}}\right)^{2} \times \underline{\mathrm{P}(1-\mathrm{P})}$

Where $\mathrm{Z}=1.96, \quad \mathrm{P}=8.3 \%, 0.083 \mathrm{~d}=5 \%, 0.05$

Therefore, $\boldsymbol{n}=\quad(1.96)^{2} \times 0.083 \times(1-0.0830)$

$$
\boldsymbol{n}=116.9, \approx 117
$$

The minimum sample size is 117 . However, 3 will be added as attrition. $\boldsymbol{n}=120$

\section{Sampling technique}

A simple random sampling technique was used to recruit subjects who satisfied the inclusion criteria.

\section{Inclusion/ Exclusion criteria}

For the control group; subjects with no family history of diabetes mellitus, normal blood pressure, normal plasma glucose level and absence of glucosuria. For case study; subjects were selected based on clinical diagnosis of diabetes mellitus.

Individuals with likely confounding factors such as obesity, family history of diabetes, high or low plasma glucose level, glucosuria, physical and medication like Acetyl salicylic acid (ASA) were excluded from being control subjects.

\section{Informed consent}

Written informed consent was obtained from all participating subjects.

\section{Ethical clearance}


Ethical clearance was obtained from the Research Ethical Clearance Committee of University of Maiduguri Teaching Hospital, Nigeria.

\section{Variable data}

A standard structured questionnaire was used to obtain some demographic information of all participants.

\section{Sample collection}

Tourniquet was applied to the upper right arm, and desired area for the sample collection was selected and sterilized using swab soaked in $70 \%$ alcohol. 3millilitres of blood, each, was drawn into Oxalate fluoride and EDTA containers. They were well mixed and clearly labeled with the subject's identification number and date as labeled on the questionnaire. The samples in Oxalate fluoride containers were centrifuged at 4000rpm for 10 minutes, plasma was obtained for glucose estimation while the whole blood in the EDTA containers were used for determination of platelet counts.

\section{Glucose estimation}

Plasma glucose was determined by the oxidase-peroxidase (enzymatic) colorimetric method as described by Trinder [22]. The testing was conducted based on manufacturers instruction (Randox laboratories, limited, UK).

\section{Platelet count determination}

The platelet count was determined by haemocytometer as described by Cheesebrough [23].

\section{Statistical analysis}

Data generated was analysed using Statistical Package for Social Science (SPSS version 20.0 for windows). Students' t-test was used for analysis of differences between means for two groups. Pearson correlations were conducted to determine associations between platelet counts and fasting plasma glucose.

\section{Results}

A total of 220 subjects; 120 diabetics and 100 non-diabetics were recruited for the study. Out of the 120 diabetic subjects, $42(35 \%)$ were males and $78(65 \%)$ were females (Table I).Table II shows distribution of diabetic subjects according to types of diabetes. Out of 120 diabetic subjects, $2(1.7 \%)$ were type I diabetes, 101 (84.1\%) were type 2 diabetes while $17(14.2 \%)$ were gestational diabetes. The sample size for type 1 diabetics $(1.7 \%)$ is too small to make any reasonable inference. There was no significant difference $(p>0.05)$ between the means of platelet counts of diabetics and controls; gestational diabetes and controls $\left(315.37 \pm 56.13 \times 10^{9}\right.$ cells $/ 1$ versus $335.98 \pm 52.29 \times 10^{9}$ cells $/$; $325.82 \pm 56.78 \times 10^{9}$ cells/l versus $335.98 \pm 52.29 \times 10^{9}$ cells $/$ l) respectively as presented in table III. In our study, the mean platelet counts Was significantly $(\mathrm{p}<0.05)$ lower in type 2 diabetics as compared to the gestational diabetics $\left(315.37 \pm 56.13 \times 10^{9}\right.$ cells $/ 1$ versus $\left.325.82 \pm 56.78 \times 10^{9} \mathrm{cells} / \mathrm{l}\right)$. This is shown in table IV. There was a positive but not significant correlation $(r=0.052 ; p>0.05)$ between platelet counts and fasting plasma glucose of diabetic subjects (table V).

Table I: Distribution of diabetic subjects based on their gender

\begin{tabular}{|c|c|c|c|c|c|c|c|}
\hline $\begin{array}{lllll}\mathbf{G} & \mathbf{r} & \mathbf{o} & \mathbf{u} & \mathbf{p} \\
\end{array}$ & G e n d e r & $\mathbf{N}$ & u m b e & $(\mathbf{n})$ & & ta & $\%)$ \\
\hline \multirow[t]{2}{*}{ Diabetic Subjects } & $\begin{array}{llll}M & \text { a } & 1 & \text { e }\end{array}$ & 4 & & 2 & 3 & & 5 \\
\hline & $\mathrm{Fe} \mathrm{m}$ a $1 \mathrm{e}$ & 7 & & 8 & 6 & & 5 \\
\hline $\begin{array}{llllll}\mathbf{T} & \mathbf{o} & \mathbf{t} & \mathbf{a} & \mathbf{l}\end{array}$ & & 1 & 2 & $\mathbf{0}$ & $\mathbf{1}$ & $\mathbf{0}$ & $\mathbf{0}$ \\
\hline
\end{tabular}

Table II: Distribution of diabetic subjects based on diabetes type

\begin{tabular}{|c|c|c|c|c|c|c|c|c|c|c|c|c|c|c|c|c|}
\hline $\mathbf{G}$ & $\mathbf{r}$ & $\mathbf{0}$ & $\mathbf{u}$ & $\mathbf{p}$ & & pe & of & Dia & & & b e r & $(\mathrm{n})$ & $\mathbf{P}$ & e n & g e & $(\%)$ \\
\hline & bet & & bje & & $\mathrm{T}$ & $\mathrm{y}$ & $\mathrm{p}$ & $\mathrm{e}$ & 1 & & & & 1 & & & 7 \\
\hline & & & & & $\mathrm{T}$ & $\mathrm{y}$ & $\mathrm{p}$ & $\mathrm{e}$ & 2 & 1 & 0 & 1 & 8 & 4 & . & 1 \\
\hline
\end{tabular}


Preliminary Evaluation of Platelet Counts of Diabetic Individuals Attending University.....

\begin{tabular}{|c|c|c|c|c|c|c|c|c|c|c|c|c|}
\hline & & & & $\mathrm{G}$ & D & $\mathrm{M}$ & 1 & & 7 & 1 & 4 & 2 \\
\hline $\mathbf{T}$ & o & $\mathbf{t}$ & $\mathbf{a}$ & $\mathbf{l}$ & & & 1 & 2 & 0 & 1 & & 0 \\
\hline
\end{tabular}

Table III: Comparison of Mean \pm SD of platelet counts in type 2 diabetics, GDM and control subjects.

\begin{tabular}{|c|c|c|c|c|c|c|c|c|}
\hline Type of Diabetes & 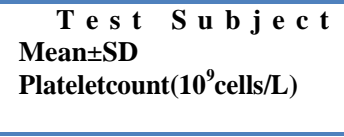 & $\begin{array}{lrr}\text { C } & \text { o } & \text { n } \\
\text { Mean } \pm \text { SD }\end{array}$ & $\mathbf{t}$ & $\mathbf{r}$ & $\mathbf{0}$ & $\mathbf{l}$ & $\mathbf{s}$ & P-value \\
\hline Tуре 2 & $315.37 \pm 56.13$ & 335.9 & $98=$ & \pm 5 & 2 & & 9 & $\mathrm{p}>0.05$ \\
\hline G D M & $325.82 \pm 56.78$ & $\begin{array}{llll}3 & 3 & 5 & 9\end{array}$ & $98=$ & \pm 5 & 2 & 2 & 9 & $\mathrm{p}>0.05$ \\
\hline
\end{tabular}

$\mathrm{SD}=$ Standard deviation and NS=Not significant

Table IV: Comparison of Mean \pm SD of platelet counts between type 2 diabetics and gestational diabetics

\begin{tabular}{|c|c|c|c|}
\hline \multirow{2}{*}{$\begin{array}{llllllll}\mathbf{V} & \mathbf{a} & \mathbf{r} & \mathbf{i} & \mathbf{a} & \mathbf{b} & \mathbf{l} & \mathbf{e}\end{array}$} & \multicolumn{2}{|c|}{ Type of Diabet } & \multirow[b]{2}{*}{ P-value } \\
\hline & $\begin{array}{c}\text { Type } 2 \\
\text { Mean } \pm \text { SD }\end{array}$ & $\begin{array}{l}\text { GDM } \\
\text { Mean } \pm \text { SD }\end{array}$ & \\
\hline Plateletcount $\left(10^{9} \operatorname{cells} / \mathrm{L}\right)$ & $315.37 \pm 56.13$ & $325.82 \pm 56.78$ & $\mathrm{P}<0.05$ \\
\hline
\end{tabular}

$\mathrm{SD}=$ Standard deviation and $\mathrm{S}=$ Significant

Table V: Correlation between platelet counts and fasting plasma glucose in diabetic subjects

\begin{tabular}{cllllllllllll}
\hline Variables & r-value & p-value \\
\hline Platelet counts and FPG & 0 &. & 0 & 5 & 2 & p & $>$ & 0 & 0 & 5
\end{tabular}

$\mathrm{SD}=$ Standard deviation and NS= Not Significant

\section{Discussion}

Platelet counts and mean platelet volume are characteristics of platelet and simple viable indicators of platelet function and can be used as biomarkers for risk of macrovascular complications in diabetics [5] [20].

In this study, mean absolute platelet count of the type 2, Gestational diabetics and control subjects was the major parameter of concern. Similarly, in a study carried out by Obeagu et al. [24] in South East Nigeria, absolute platelet counts were found to be less in male and female diabetics compared to male and female controls, respectively with p-value $>0.05$. Nneka et al. [18] reported concurring results in the same region. Zuberi et al. [4] found relating results from Pakistan; Elnour and Muddathir [7] also showed concurring observations among pregnant Sudanese women.

The platelet counts of diabetic patients cutting across genders and types of diabetes correlates positively with the levels glycaemic control defined by the level of blood sugar of such patients [25].Our study shows statistically significant decrease $(p<0.05)$ in the mean absolute platelet counts of patients with type 2 diabetes $(315.37 \pm 56.13)$ when compared to patients with GDM (325.82 \pm 56.78$)$. Previous studies on platelet indices of diabetes in this locality did not compare counts among the types of diabetes. Raised platelet counts in GDM may be linked to some diabetes induced platelet related complications associated with mortality and morbidity in pregnancy.

\section{Conclusion}

Routine platelet counts result is a good index for evaluation thrombotic function of diabetic patients, but more useful in conjunction with testing the overall functionality of the coagulation cascades.

\section{Acknowledgement}

The authors wish to acknowledge the management of University of Maiduguri Teaching Hospital for the Ethical approval given and the contributions of their colleagues.

\section{References}


[1]. Baynes HW, Classification, Pathophysiology, Diagnosis and Management of Diabetes Mellitus. J Diabetes Metab 6: $2015,541$.

[2]. Corkey BE, Insulin resistance and high levels of insulin and lipids all precede the development of metabolic dysfunction. Which metabolic factor is to blame? What causes type 2 Diabetes? TheScientist Magazine. Available from: http://mobile.thescientist.com/article/46391/what-causes-type-2-diabetes. [Last accessed on 2016 September 9].

[3]. Schneider, D.J., Factors contributing to increased platelet reactivity in people with diabetes. Diabetes Care, 32, (4), 2009:525-527

[4]. Zuberi B F, Akhtar N, Afsar S, Comparison of mean platelet volume in patients with diabetes mellitus impaired fasting glucose and nondiabetic subjects. Singapore Med J, 49 (2), 2008: 114.

[5]. S. Gioia, A. Cerekja, G. Larciprete, C. Vallone, E. Demaliaj, M. T. Evangelista, M. Guglietta and J. Piazze, Gestational diabetes: Is it linked to platelets hyperactivity?, Platelets, 20:2, 2009, 140-141.

[6]. Aygül Çeltik, Barış Akıncı, Tevfik Demir, Mean Platelet Volume in Women with Gestational Diabetes. Turk J Endocrinol Metab 20, 2016, 48-53.

[7]. Shweda Elnour, Abdel Rahim Mahmoud Muddathir. Assessment of mean platelet volume and platelets histogram among Sudanese pregnant women with gestational diabetes mellitus. American Journal of Research Communication, 1(12), 2013, 445-450.

[8]. Sicree, R., Shaw, J., and Zimmet, P., The Global Burden. Diabetes and Impaired Glucose Tolerance. Prevalence and Projections. Diabetes Atlas, 2006, 16-103.

[9]. Yngen M, Norhammar A, Hjemdahl P, Walle'n NH, Effects of improved metabolic control on platelet reactivity in patients with type 2 diabetes mellitus following coronary angioplasty. Diab Vasc Dis Res 3, 2006, 52-56.

[10]. Angiolillo, D.J., Bernardo, E., Ramírez, C., Insulin therapy is associated with platelet dysfunction in patients with type 2 diabetes mellitus on dual oral antiplatelet treatment. Journal of the American College of Cardiology,48(2), 2006.

[11]. Vaidyula VR, Boden G, Rao AK, Platelet and monocyte activation by hyperglycemia and hyperinsulinemia in healthy subjects. Platelets: 17(8), 2006, 577-85.

[12]. Keating, F.K., Sobel, B.E and Schneider, D.J., Effects of increased concentrations of glucose on platelet reactivity in healthy subjects and in patients with and without diabetes mellitus. American Journal of Cardiology, 92(11), 2003, 1362-1365.

[13]. Assert, R., Scherk, G., Bumbure, A., Pirags, V., Schatz, H and Pfeiffer, A.F, Regulation of protein kinase C by short term hyperglycaemia in human platelets in vivo and in vitro. Diabetologia, 44(2), 2001, 188-195.

[14]. Tschoepe, D., The activated megakaryocyte - platelet-system in vascular disease: focus on diabetes. Seminars in Thrombosis and Hemostasis, 21(2), 1995, 152-160.

[15]. Westerbacka, J., Yki-Järvinen, H., and Turpeinen, A., Inhibition of platelet-collagen interaction: an in vivo action of insulin abolished by insulin resistance in obesity. Arteriosclerosis, Thrombosis, and Vascular Biology, 22(1), 2002, $167-17$.

[16]. Ferreira, I.A., Eybrechts, K.L., Mocking, A.I., Kroner, C., and Akkerman, J.N., IRS-1 Mediates Inhibition of Ca2+ Mobilization by Insulin via the Inhibitory G-protein Gi. Journal of Biological Chemistry, 279 (5), 2004, 3254-3264.

[17]. Santilli F, Formoso G, Sbraccia P, Averna M, Miccoli R, Di Fulvio P, Ganci A, Pulizzi N, Lattanzio S, Ciabattoni G, Consoli A, Lauro R, Patrono C, Davi` G., Postprandial hyperglycemia is a determinant of platelet activation in early type 2 diabetes mellitus. J Thromb Haemost, 8, 2010, 828-37.

[18]. Nweke Ifeoma Nneka, Mbah Anthony Uchenna, Ezeala Christian Chinyere, Ewosiobi Augustine Ikechukwu, Okechi Obioma Onyemeachi and Eroegbusi Joseph Nwobi, Platelet Activity in Patients with Type 2 Diabetes in Eastern Nigeria. Research Journal of Pharmacology 6(3), 2012, 48-51.

[19]. Muhammet Erdal Sak, Hatice Ender Soydinç, Ali Özler, Mehmet Sıddık Evsen, Abdülkadir Turgut, Sibel Sak, Talip Gül, Platelet profile in patients with gestational diabetes: a retrospective study. J Turkish-German Gynecol Assoc, 13, 2012, 223-6.

[20]. Premnath Raman, Prardhana Reddy Kundur, A Correlation between Diabetic Ischaemic Maculopathy and Platelet Indices. IOSR Journal of Dental and Medical Sciences, 15 (1), 2016, 51-56.

[21]. Ogbera, A.O and Epebegh, C., Diabetes mellitus in Nigeria: the past, present and future. World Journal of Diabetes: 5(6), 2014, 905-911.

[22]. Trinder, P., Determination of Blood Glucose using an Oxidase- Peroxidase System with a Non-carcinogenic Chromogen. Journal of Clinical Pathology, 22(2), 1969, 158-61.

[23]. Monica, C., Laboratory practice in Tropical Countries ( $2^{\text {nd }}$ ed), (Cambridge University Press: Repro India, India ;2006), Counting white cells and platelets, 317-318.

[24]. Obeagu, E.I., Okoroiwu, I.L. and Obeagu, G.U., Some haematological variables in insulin dependent diabetes mellitus patients in Imo state Nigeria. International Journal Of Current Research In Chemistry And Pharmaceutical Sciences, 3(4), 2016.

[25]. Uko EK, Erhabor O, Isaac IZ, Abdulrahaman Y, Adias TC, et al., Some Haematological Parameters in Patients with Type-1 Diabetes in Sokoto, North Western Nigeria. J Blood Lymph 3, 2013, 110. 